latest vessels of the British navy were, as has been mentioned above, doing duty on the Mediterranea and foreign stations, from which they could not be spared, even for such an important occasion as the coronation of the King.

\section{ELECTRICAL RESONANCE AND ITS RELATION TO SYNTONIC WIRELESS TELEGRAPHY-II.}

$$
\text { BY A. FREDERICK COLLINS. }
$$

(Continued from page 120.)

Having developed the theory that light and electric or Hertzian waves are electromagnetic and that both originated from the same cause and are propagated by the same medium, the next step toward the new

\section{FIG. 4.}

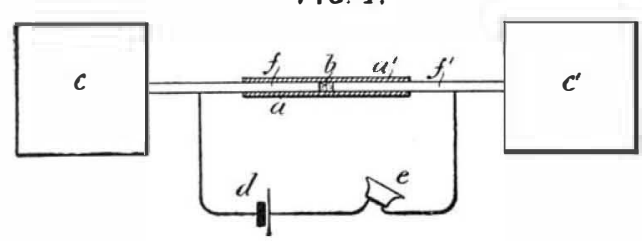

that electric waves acted on metal filings very much like light waves on selenium, i. e., lowered its re sistency; these filings were placed in a glass tube for convenience in operating, and to its evolution is largely due the practicability of the wireless telegraph. Branly's radio-conductor, as he named the tube, entirely supplanted the wire-ring detector of Hertz, owing to its wonderful sensibility to the electric waves. Lodge renamed this electric eye a coherer, which has almost entirely supplanted its original appellation of radio-conductor. The coherer with battery and tel? phone receiver shown diagramatically in Fig. 4 is the fundamental receiving apparatus required for wireless telegraphy.

\section{WIRELESS TELEGRAPHY.}

The apparatus employed in wireless telegraphy consists of the Ruhmkorff coil and oscillator, as in the Hertzian experiments, but with the addition of a long vertical wire or antenna, suspended from a mast, it lower terminal connected with one arm of the oscillator; a second wire leading from the opposite oscillator arm to a sheet of metal in the earth. Fig. 5, A, shows the arrangement. The receiving device consists of the coherer with a vertical wire leading from one of its conductor plugs to a mast as in the transmitter; the opposite coherer conductor plug is conmitter; the opposite coherer conductor plug is con-
nected with an earthed plate of metal. In series with nected with an earthed plate of metal. In series with
the coherer are a battery and relay, and in an auxilthe coherer are a battery and relay, and in an auxil-
lary circuit are placed the tapping device to decohere the filings in the tube and a Morse register for recording the messages on tape. The receiver is illustrated in Fig. $5, B$. Now when the waves are emitted by the transmitter, $A$. at a distance from the receiver, $B$, they are propagated through the electro-magnetic medium or ether, and every impinging wire on the vertical wire attached to the coherer, $B$, decreases its resistance from thousands of ohms to a few tens or even less; the resistance of the circuit, including the coherer, battery and relay is now reduced sufficiently to offer little opposition to the current from the battery, the relay armature is drawn into contact and actuates the circuit controlling the register.

$$
\text { RESONANCE. }
$$

With this brief description of the modus operand for wireless telegraphy it will be interesting to ascertain the laws governing the electrical resonance effects between the transmitter and receiver and the appara-

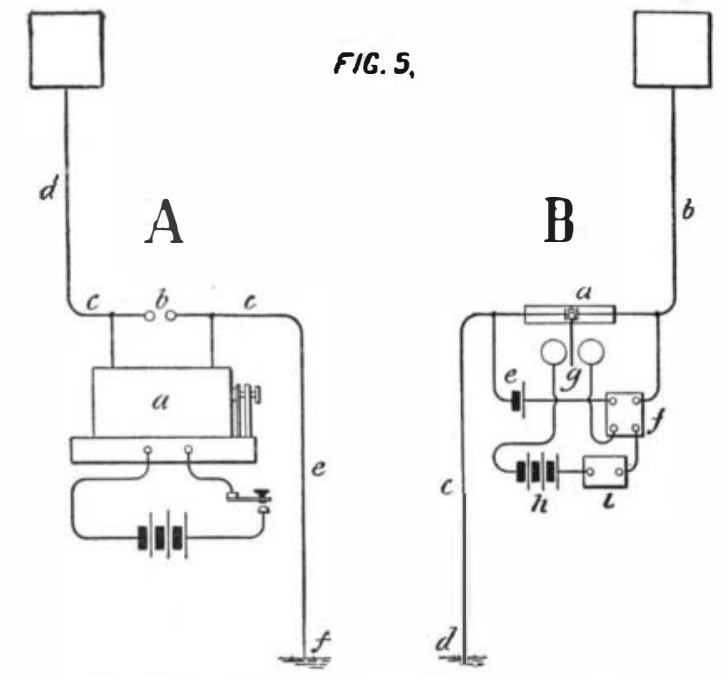

tus necessary to transmit waves to "any one or mor of a number of different instruments in various localities." This is accomplished by prolonging a series of rapid electric oscillations of a particular frequency on the transmitter and having the receiving circuit so balthe transmitter and having the receiving circuit so bal-
anced in its coefficients of inductance, capacity and resistance as to respond to that frequency or some multiple or sub-multiple of it. This is clearly shown in the case of Lodge's syntonic jars. Fig. $6, A$, is Leyden jar, 1, having a spark-gap, 2, and a circuit formed of a rectangular conductor, 3 . At B1, is a second Leyden jar of equal capacity to $A 1$, a sparkgap, 2, of microscopic size and a circuit, 3, made variable by the sliding wire, 4 . If the jar, $A 1$, is now charged and then discharged through the gap, 2, oscillations will be set up in the circuit, $A 3$, of definite frequency and if the inductance capacity and resist ance of both circuits, $A 3$ and $B 3$, are equal, then osci lations having the same periodicity will occur in $B 3$ The scale upon which these experiments are made may be greatly extended; the Ruhmkorff coil and Hertz oscillator may be substituted for the Leyden jar at $A 1$, and a coherer for the micrometer spark-gap of $B 2$. But in substituting these essential factors two great But in substituting these essential factors two great
difficulties are encountered; first, an open circuit, i. e. difficulties are encountered; first, an open circuit, i. e.,
Hertz oscillator, emits waves with such energy that Hertz oscillator, emits waves with such energy that
only two or three swings of the high frequency current take place before it is damped out or the current

$$
\text { FIG.6. }
$$
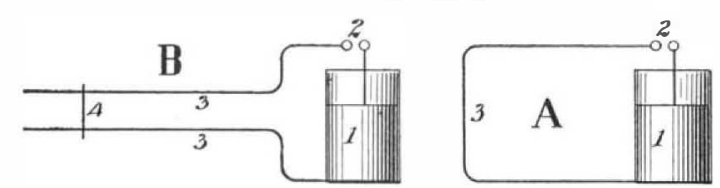

dissipated, as shown in the diagram, Fig. $7, A$. Wave emitted by this system are propagated to great distances, but the oscillations producing them are not sufficiently prolonged to create oscillations of similar frequency in the receiving circuit. In the closed cirfrequency in the receiving circuit. In the closed cir-
cuit oscillator of the Lodge syntonic jar type the oscillations are quite persistent and in consequence the emitted waves are very feeble; this precludes its use for commercial wireless telegraphy. Such a closed circuit oscillator will set up in a receiver in tune with it oscillations of remarkable persistency, depicted graphically in Fig. $7, B$. The second difficulty in changing from the experimental apparatus to that changing from the experimental apparatus to that required in practice is the tremendous additional ca-
pacity loaded on the oscillator and coherer circuits by pacity loaded on the oscillator and coherer
connecting one arm of either to the earth.

FIC.7.
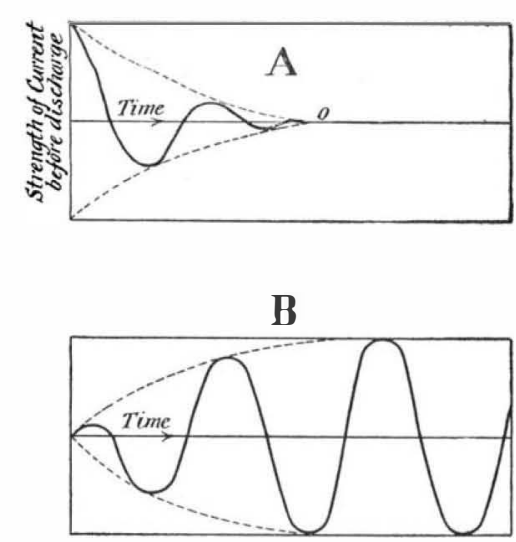

The capacity of the earth is so great that practically all oscillators and coherer circuits are tuned or syntonized, and by inserting other values of capacities and inductances in the form of inductance coils and condensers, the value of the earthed systems is but little changed

SYNTONIZATION.

To systems employing pure resonance effects in which both transmitting and receiving circuits are tuned by inductance and capacity, the name syntonic has been given. By clever arrangement of the devices the objectionable features of the closed oscillator are partially eliminated and its good features partly re tained, in other words, a compromise has been effected.

The three principal syntonic systems are the SlabyFIG.8.

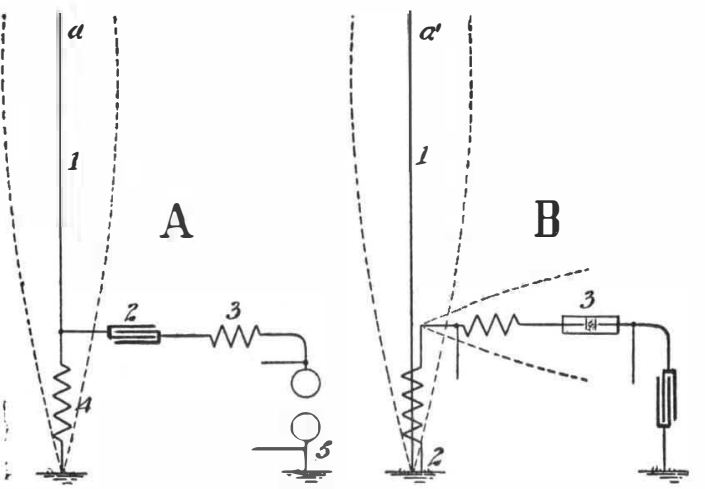

Arco, the Braun and the Marconi. The Slaby-Arco syntonic wireless telegraph is shown in diagram, Fig. $8, A, B$. It is assumed by the inventors that electric oscillations in the vertical wire, 1 , are like the me chanical vibrations of a flexible steel bar with the greatest amplitude at $a, a^{\prime}, A$. B. with the ether as the connecting medium. The coherer then should be at tached to the highest point of the wire, $a^{\prime}$. The terminal of the vertical wire or antenna forming contact with the earth is, accordirg to Dr. Slaby's theory, the nodal point of the electric waves. At this point a ses ond wire, 2, having inductance and capacity equal to the wire, 1 , is connected in, with the opposite terminal attached to the coherer, 3 , thus the amplitude of the wave is again the greatest, and the maximum effect obtained without attaching the coherer to the upper terminal of the vertical wire. The transmitter is arranged similarly in its relation to the antenna. An adjustable condenser, 2, and inductance coil, 3, permit the periodicity of oscillation to be changed to a

\section{FIG. 9 .}
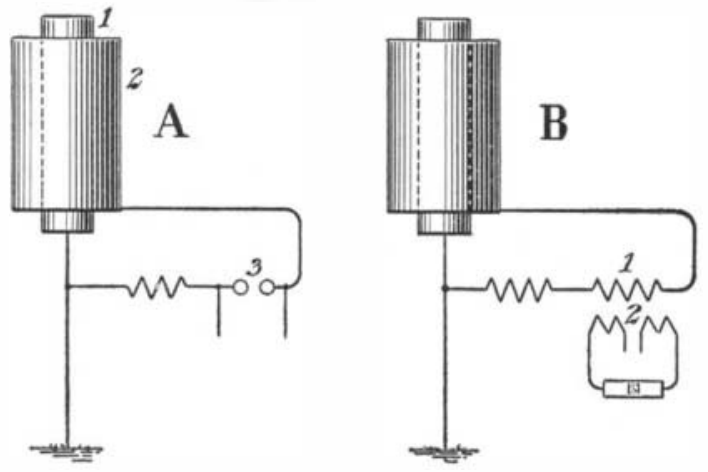

value suitable for the receiver. The coil, 4 , serves to regulate the harmonies between the vertical wire emitting them and the oscillator system producing them. One terminal of the oscillator system, 5, leads to earth, which forms, virtually, a loop or closed cir cuit as in the Lodge syntonic jar. This system was exhibited by Dr. A. Slaby and Count d'Arco before the German Emperor in 1899 when two messages were sent and received simultaneously from different stations without interfering.

In the Marconi syntonic wireless telegraph system the feeble radiation of the closed circuit has been obviated by a widely different method from that of Slaby. Marconi has worked along the lines laid down by Lodge, producing the emitter shown in Fig. 9, $A$. It consists essentially of two concentric copper cylin ders, one within the other, but separated by an insulating film of air. The inner cylinder, 1 , is connected with the earth and one terminal of the spark-gap, 3. The outer cylinder, 2, is connected to the opposite terminal of the spark-gap, the whole representing a huge Leyden jar, the current surging to and fro, equalizing the difference of potential. The receiver is equalizing the difference of potential. The receiver is of the transmitter. One of the greatest improvements in commercial apparatus is that of the transformer coil shown, 1, 2. The coherer, instead of being placed in the electric wave system direct, is arranged in a separate circuit. The free periods of the oscillations set up are not affected by the high resistance of the coherer, and the oscillations may be stepped up or stepped down, as in the case with commercial alterstepped down, as in the case with commercial altertested between Biot and Calvi, near Nice, by Marconi, who has since fully described the equipment in a paper before the Society of Arts.

Another syntonic wireless system is that of Dr. F. Braun and has been described in the Scifentific American Supplement. Fig. $10, A$ and $B$, shows the arrangement of the transmitter and the receiver. $J$ is the secondary of the induction coil, $s$ the spark-gap, $c, c$ secondary of the induction coll, $s$ the spark is $c$, $c$ corming a closed circuit, the oscillations being very persistent; $M$ is the secondary of the transformer, and with the conductors $\frac{\lambda}{4}$ an open oscillator system is produced. This arrangement has all the advantages of the closed and open oscillators combined. The re-

FIG.10.

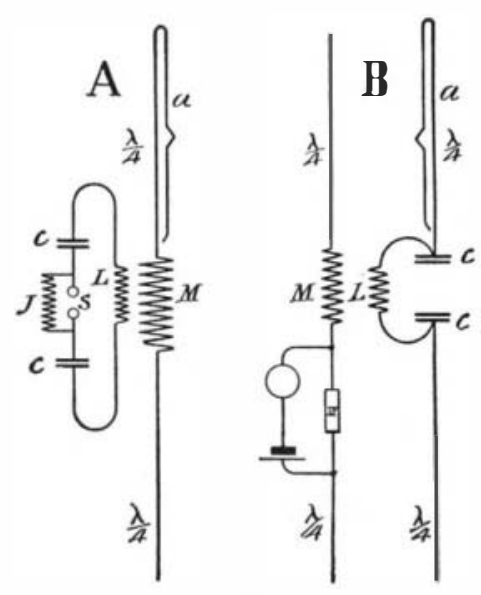

ceiver, $B$, consists of the vertical wire, $a$, condensers, $c, c$, and the inductance coil, $\boldsymbol{L}$, forming the closed circuit and the secondary, $M$, and conductors, $\frac{\lambda}{4}$ included in one of them is the coherer and receiving apparatus. The conductors marked $a, a, A$ and $B$, are the antenna and all others marked $\frac{\lambda}{4}$ are of equal length, but are coiled up loosely. This system is now in use in Germany and has given satisfaction over distances of 40 miles. 
This represents the state of the art wherein the Thultaneous transmission of wireless messages in the same field of force without interference is accom plished at the present time. The whole future of wireless telegraphy depends on the great problem o electrical resonance in its relation to the requirement of practice, rather than on the distance over which the waves may be propagated. Wireless telegraphy is a new art with possibilities practically unlimited when a simple, practical and sure method is attained for syntonizing the instruments. The laws of high-fre quency, high-potential currents are well understood, as are those of electrical resonance, but the function of the earth being imperfectly understood has blocked the way very materially to the application of these principles.

The evolution of wireless telegraphy has been rapid and in less time than was required to perfect the telephone a system of wireless transmission of intelligence should be in operation fulfilling all the requirements of commercial usage.

\section{THE SNOQUALMIE FALLS POWER PLANT.}

The electrical power transmission plant at Snoqualmie Falls, State of Washington, if not the greatest in the amount of power produced in the far West, is in many respects, the most remarkable. The natural advantages at this point for a power plant of this kind are not excelled anywhere, and though the obstacles presented offered but little difficulty, from an engineering point of view, the skill with which every material eature of the undertaking has been subordinated in order to secure intended results, has been so masterly, as to make this famous plant one absolutely unique in the annals of like undertakings. Art has here supplemented natural forces and the result has yet to be surpassed.

Niagara is greater in many respects; less in the attitude of the fall, but presenting no problem of economical administration of the water flow; but at Snoqualmie severe questions of water storge, seasonal variations in the flow, floods and drought, had to be confronted. A combination of almost every feature embraced in transmission of electrical energy is demonstrated in this wonderful plant.

The Snoqualmie River rises in the Cascade Mountains and drains a comparatively smail area, but the rainfall, from 90 to 150 inches annually, assures a volume to the stream entirely disproportioned to the extent of the watershed. Moreover, the sources of the river are amid snows, accumulated during the winter months and yielding constant reinforcements during the season of droughts. Floods pouring 10,000 cubic feet of water a second occur every season, the flow diminishing to one-tenth that amount in the month of September; but the regulation of the flow offers no difficulties. Lakes abound in the upper courses of the river with narrow outlets which, if dammed, would hold the superabundant floods and permit an ultimate and regular volume in the stream, and afford, at al times, 200,000 available horse power. At present 30, 000 horse power is produced. The greater power may be had whenever the rapidly extending manufacturing interests of the country demand it.

Thirty-one miles from Seattle, the Snoqualmie de scends in one leap over a basaltic rock barrier 270 feet high. Less than four years ago the scene at this poin was one of wild grandeur, and forest solitude. Today, a transformation is presented. The banks have been restrained and terraced. The great pines have disappeared. Dwellings and apartments of architectural symmetry decorate the landscape, and a busy community has grown up beside the cataract.

The Snoqualmie Light and Power Company was or ganized in 1898, and soon after surveys of the river and watershed were undertaken, and plans for their development adopted.

A dam of concrete was constructed just beyond the crest of the falls, for the purpose of raising the low water elevation of the river to a minimum depth of 8 feet. The dam is 218 feet long between piers, and varies in height from 3 to 10 feet, with a level varies in height from 3 to 10 feet, with a level
crest 8 feet wide, sloping up and down stream, with crest 8 feet wide, sloping up and down stream, with
base varying from 16 to 35 feet in breadth. The dam is strengthened by steel rails fastened into the rock bottom and projecting upward into the concrete. I is calculated, if the demand for power required it, that the present dam could be increased to a height of 50 feet, and a lake formed 15 miles in length and of an average depth of 25 feet. increasing the available power to 200,000

Abolit 100 feet above the dam. a shaft is sunk, $10 \times 27$ feet in dimensions, descending 270 feet to the leve of the river below the falls. A tunnes, 12 feet wise, and 24 feet high, is driven from the face of the ledge below the falls, to intersect the shaft. The tunnel is the toot of the

is a chamber 200 feet in lensth, 40 feet wide, and $\mathbf{3 0}$ eet high, excavated in the solid rock. This chambe is unique in power transmission plants, housing, as it does, water-wheels and electric generators, 270 feet underground. The tunnel underneath forms the tailrace. The floor of the chamber is of concrete, the walls are of rock, and are whitewashed. Hundreds of incandescent lamps illuminate this great artificially constructed cave. As more water-wheels and generators are required, this chamber will be continued to an additional length of 200 feet.

The main shaft has three compartments; an ele vator in the center, with a chamber for the great cables, and a penstock on each side. The steel bulkhead composing the central shaft extends from the surface to the chamber below, and is built of stee ides on the outis a steel pipe 71/2 feet in diameter, passing through a concrete roof, which keeps th shaft watertight. The plates are in eight-foot courses, 1 inch in thickness at the lower half, and decreasing
to $\%$ and $1 \%$ inch. The joints are heavily riveted and to $\pi$ and $1 / 2$ inch. The joints are heavily riveted and calked. At a depth of 250 feet the penstock reaches the chamber and connects with a horizontal, cylin drical receiver, which rests on a rock bench at the sicie of the chamber, 12 feet above the floor for almost the entire length. The diameter of the receiver varies from 10 feet for half its length, to 8 feet for the balance. It is built of 1-inch plates. The weight of the penstock and receiver is 225 tons. and the weight of the water column in the penstock is 340 tons.

Water is taken direct from the river into the in take. a massive chamber of concrete with walls 25 feet high. and 6 feet thick. To keep out floating obstructions the front of the intake is protected by a grating of $12 \times 12$ timbers with a 12-inch space between each. The headbay is further nroterted by a screen o flat, steel bars for keeping out small dehris. In the chamber are installed four wheel units, each rleveloping 2,500 horse power, and directly connected to its

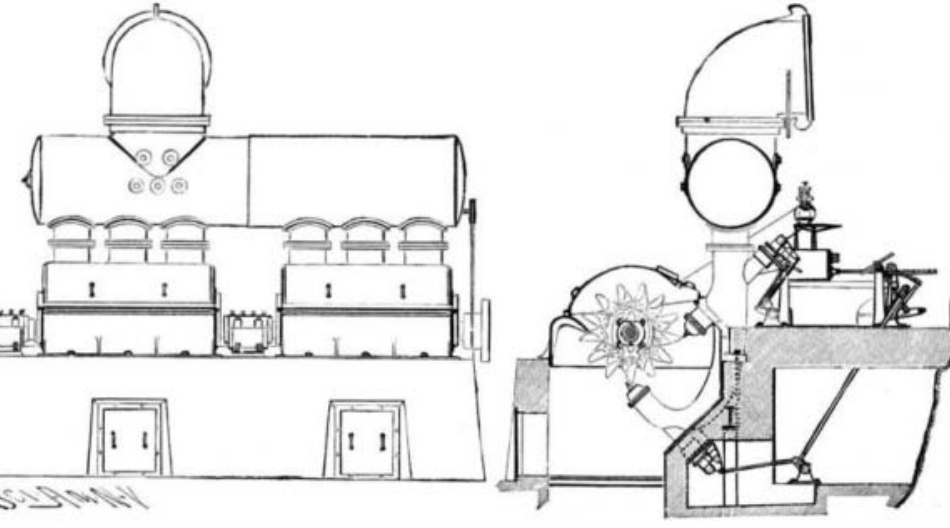

FRONT VIEW AND CROSS-SECTION OF RECEIVER AND WATER WHEELS OF THE SNOQUALMIE POWER PLANT.

generator. The vessels are of the tangential type The receiver has four supply openings controlled by individual double-screen gate valves, of 48 inches inside diameter, weighing 23,000 pounds each. This receiver is horizontal, and the openings are on its side, and open toward the cavity. Bolted direct to the
gate valve is an elbow casting that directs the water gate valve is an elbow casting that directs the water
downward into the distributing receiver. This elbow is 48 inches inside diameter, and is bolted directly to the flanged opening of the distributing receiver. The water flowing into the receiver is discharged from the six openings along the bottom, into the six multiple nozzles that direct and regulate the water that is applied to the wheels. The six wheels are divided into two groups of three, each being in a separate housing, with a bearing between. Regulating lips are used on the nozzles, which throw a perfect and unbroken stream and are controlled by a governor. The wheels are 45 inches in diameter, with thirteen buckets each. The weight of each unit is about 100,000 pounds, ex clusive of the weight of water in the receiver house. The foundations were required to be of a massive and substantial character. The tailrace is beneath the foundations, so that the water drops into it from the wheels and flows out into the river below the falls. The generators are of the revolving armature type The generators are of the revolving armature type
and deliver a 3-phase current: each weighs 100,000 pounds and stands 14 feet high. The armature wind ing consists of 266 bars with one bar to each slot and is closed-circuit winding. The speed is 300 revolutions per minute.

There are provided two separate 125 -volt exciters, wheel mounted on steel bi From the feed panteel $h$ From the feed panels of current up the elevator sha current up the elevator sha
transformer house is firepr transformer
dimensions.

The character of the transmission line is, gene ous, though in places, flat tion is made of the line's condition. The right of way is cleared for a distance of 300 feet on each side of the line. The transmission lines are of aluminium The conductivity of this metal is 60 per cent that of copper, and consequently the cables are 66 per cent greater in cross section than copper cables of the same capacity. Even at the increased size the saving in weight by the use of aluminium is nearly 50 per cent. The cost also is less.

The terminal station at Seattle is located in the business district and is a building of large dimensions and of considerable architectural pretension.

The street railroads of Seattle, many manufactories, beside public and private lighting, are supplied by the Snoqualmie Company. Tacoma, a city of 40,000 inluabitants, which is supplied from the falls, is also provided with a large and fully equipped substation.

The next move will be to connect with the city of Everett with its population of $\cdot 10,000$ and extensive lumbering establishments. This work is now in hand.

\section{More News of the Gallie. Ferraris Award.}

The commission for the Galileo Ferraris award, which was instituted in 1898, composed of representatives of the Executive Committee of the Association of the General Italian Exposition, in Turin, 1898, of the Chamber of Commerce and Arts, of the Royal Academy of Sciences and of the Royal Italian Industrial Museum of Turin, has decided to reopen an international competition for the conferring of this premium on the occasion of the inauguration, whicin will take place in the second half of September next, of the monument rious scientist.

The premium consists of 15,000 lire and interest from 1899 up to the date of the assignment, and will be conferred upon the author of any invention from which results a notable progress in the industrial applications of electricity.

Competitors can present papers, projects and drawings, as well as machines, apparatus or constructions relating to their inventions.

The jury nominated by the association above named will have most ample powers to execute practical

Competitors must present their requests and deliver their works, machines, apparatus or anything else connected with their inventions, not later than the 18th day of September, 1902 , at the office of the secretary of the association, which office is located at the administrative committee headquarters of the First International Exposition of Modern Decorative Art, 1902, in the palace of the Chamber of No. 28.

\section{The "Cedric" Launched.}

The new steamship "Cedric," built by Messrs. Harland \& Wolff for the White Star Line, was launched at Belfast on August 21. She is a vessel of 21,000 tons gross. Her length is 700 feet and she is 75 feet beam.

\section{Tunnel Signals for the New York Centra}

The New York Central Railroad has tested the experimental installment of the Miller visible engine signal and direct-circuit on all its trains running through the Park Avenue tunnel. The test is said to have been very successful, the engine signals working perfectly and duplicating the block signals. There are two sets of signals in the cab of the engine, one in the front and the other in the rear, to be used when the engine moves back. When the track is clear a white light is displayed, but as soon as danger threatens, the red light in the lower bulb glows red, n matter what the indications of a block-signal may be.

\section{The Current Supplement.}

The current Strplement is replete with articles that cover almost every field of science. The naval architect will read with interest the description of the building of the battleship "Nebraska" and Mr. Fred T. Jane's shrewd criticism of the "Belleisle" experiment and his study of an ideal conning tower. Engineers will doubtless appreciate the discussions of experiments on railway and road bridges and a description of the largest hydro-electric plant in Europe. Of no slight importance is a copiously illustrated account of the Meray-Rozar electrotypographic machine, as well as a report on the international exhibition of alcohol motors. Other articles of interest are Mr. Henry's paper or Chinese drugs and medicinal plants. and an account of physiological effects of diminished air pressure. "Psychological Apparatus" is the title of an interesting essay. Mr. Mason's monograph on the harpoon is con. cluded. That the Trade Notes and Selected Formulæ also find their place in the current Supplament goes without saying. 